ETNOGRAFIA DE PRÁTIC RELACIONADAS À AGRICULTUR ALIMENTAÇÃO EM COMUNIDA RURAL NO LITORAL NORTE RIO GRANDE DO 


\section{ETNOGRAFIA DE PRÁTICAS RELACIONADAS À AGRICULTURA E ALIMENTAÇÃO EM COMUNIDADE RURAL NO LITORAL NORTE DO RIO GRANDE DO SUL}

\section{A N A PAULA DE CARLI}

UNIVERSIDADE FEDERAL DO RIO GRANDE DO SUL, BRASIL

MARIANA OLIVEIRA RAMOS

UNIVERSIDADE FEDERAL DO RIO GRANDE DO SUL, BRASIL

$$
\text { J O A N A RA U N B A S I }
$$

UNIVERSIDADE FEDERAL DO RIO GRANDE DO SUL, BRASIL

\section{D I A E FERNANDES DA LUZ}

UNIVERSIDADE FEDERAL DO RIO GRANDE DO SUL, BRASIL

\section{CAROLINA MICHELON TERME}

UNIVERSIDADE FEDERAL DO RIO GRANDE DO SUL, BRASIL

$$
\text { R U M I REGIN A KU B O }
$$




\title{
ETNOGRAFIA DE PRÁTICAS RELACIONADAS À AGRICULTURA E ALIMENTAÇÃO EM COMUNIDADE RURAL NO LITORAL NORTE DO RIO GRANDE DO SUL
}

\begin{abstract}
Resumo
O presente artigo apresenta algumas reflexões geradas no processo de execução do projeto "Promoção do desenvolvimento rural sustentável na Região Nordeste do Rio Grande do Sul: extrativismo, saberes e fazeres locais e conservação ambiental'. Este projeto buscou problematizar: i) de que forma modos de vida específicos podem ser revalorizados, em um contexto de conservação da Mata Atlântica? ii) como se articulam as dimensões locais e da sociedade abrangente, no sentido de fomentar possibilidades de desenvolvimento rural com o reconhecimento e o respeito à alteridade? $\mathrm{O}$ artigo enfatiza as relações entre as pessoas e a natureza nas narrativas sobre as práticas atuais e passadas de agricultores moradores de áreas de encosta do Litoral Norte do Rio Grande do Sul. No processo de constituição das narrativas buscamos compreender como os espaços são organizados, conectando plantas, animais, água a uma lógica produtiva e de continuidade da vida. Enfim, destacamos alguns elementos que problematizam as relações entre esse modo de vida e o debate sobre o desenvolvimento rural.
\end{abstract}

Palavras-chave: práticas locais, patrimônio cultural, diversidade socioambiental, desenvolvimento rural.

\section{ETHNOGRAPHY OF PRACTICES RELATED TO AGRICULTURE AND FOOD HABITS IN A RURAL COMMUNITY OF THE NORTHERN COAST OF RIO GRANDE DO SUL}

\begin{abstract}
This article presents some reflections generated in the implementation of the project " Promotion of sustainable rural development in northeastern Rio Grande do Sul: extraction, local knowledge and environmental conservation". This project sought to discuss: i) how specific ways of life may be revalued in the context of the Atlantic Forest conservation practices? ii ) how to articulate the local and wider society, to foster opportunities for rural development with recognition and respect for otherness dimensions? The article emphasizes the relationship between people and nature in the narratives about the past and present practices of farmers living in hillside areas of the North Coast of Rio Grande do Sul. In the constitution of the narrative process we seek to understand how spaces are organized, connecting plants, animals, water for productive logic and continuity of life. Finally, we highlight some elements that problematize the relationship between this way of life and the debate on rural development.
\end{abstract}

Keywords: local practices, cultural heritage, social and environmental diversity, rural development. 


\section{ETHNOGRAPHIE DE PRATIQUES LIES A L'AGRICULTURE ET DE L'ALIMENTATION EN COMMUNAUTE RURALE DANS LE NORD DE LA COTE DU RIO GRANDE DO SUL}

\section{Résumé}

Cet article présente quelques réflexions générées dans le processus de mise en œuvre du projet «Promotion du développement rural durable dans le nord-est de Rio Grande do Sul: extractivisme, les savoir et les pratiques locales et conservation de l'environnement.» Ce projet visait à discuter: i) la façon dont les ces modes de vie localisées peuvent être revalorisées dans le contexte de la conservation de la Mata Atlantica (forêt atlantique), ii) comment ils articulent les dimensions locales et de la société inclusive, afin de favoriser les possibilités de développement rural, reconnaissance et le respect de l'altérité? L'article met l'accent sur la façon de montrer les relations entre les gens et la nature dans les récits sur les pratiques passées et actuelles des agriculteurs vivant dans les zones de collines de la côte nord du Rio Grande do Sul. Ce processus de constitution de ces récits cherchent à comprendre comment les espaces sont organisés reliant les plantes, les animaux, l'eau à une logique productive et la continuité de la vie de ces personnes. Enfin, nous mettons en évidence certains éléments qui remettent en question la relation entre ce mode de vie et le débat sur le développement rural.

Mots-clés: pratiques locales, le patrimoine culturel, la diversité sociale de l'environment, le développement rural.

Endereço da primeira autora para correspondência: PGDR - UFRGS - Av. João Pessoa, 31, CEP 90040-000, Porto Alegre - RS - Brasil. E-mail: anapaulapinta@yahoo.com.br 


\section{INTRODUÇÃO}

Diante dos reiterados discursos que vinculam a diversidade cultural e manutenção da riqueza ambiental (CNUMAD 1995, Sachs 2000), a discussão sobre conservação da biodiversidade tem alavancado alguns debates no âmbito do desenvolvimento rural (Kageyama 2008, Schneider 2010). Nesse sentido, a questão ambiental aproxima uma variedade de grupos sociais a conflitos em torno da apropriação territorial e de recursos naturais (Diegues 2000, Little 2002, Gerhardt e Almeida 2003), vindo a reelaborar conflitos anteriores sob uma nova linguagem, o que alguns autores têm designado de ambientalização dos conflitos sociais (Lopes 2006). Conforme Lopes (2006:34) o termo indicaria "um processo histórico de construção de novos fenômenos, associado à interiorização pelas pessoas e pelos grupos sociais e, no caso da "ambientalização", darse-ia uma interiorização das diferentes facetas da questão pública relacionada ao "meio ambiente".

Nesse contexto, as diferentes instâncias institucionais em nível internacional, nacional, estadual e local apontam para novas diretrizes relacionadas ao mundo rural e diversos atores aproximam-se dos diferentes grupos que compõem o universo do rural. Estas novas diretrizes apresentam-se na forma de legislações, políticas públicas, ações de organizações públicas e privadas e com isso, pode-se presumir que a paisagem, os hábitos, e as técnicas sejam afetados. Conforme Carneiro (1998: 55) é na integração de espaços com lógicas bas- tante adversas que se pode "assegurar a identidade do grupo que experimenta uma consciência de si na relação de alteridade com os de fora", o que pode resultar em formas de distinção que motivam processos de segregação em graus e conformações distintas, ${ }^{1}$ ou interações outras que podem conformar processos de integração, também em graus distintos. ${ }^{2}$ Nesses movimentos distintos, se reconhece que a manutenção da riqueza socioambiental apresenta um alicerce profundo nas relações de trocas materiais e simbólicas entre todos os atores sociais representantes dessas instâncias institucionais distintas. De forma a melhor compreender as repercussões desses arranjos institucionais em contextos locais, nossa atenção temse voltado para as práticas sociais, sobretudo a partir das relações com o ambiente, compreendendo que tais práticas assentam-se em um conhecimento local ou tradicional, ao mesmo tempo em que abrigam o novo, tudo isso perpetuando a continuidade destes grupos.

O presente artigo apresenta algumas reflexões geradas no processo de execução do projeto "Promoção do desenvolvimento rural sustentável na região Nordeste do Rio Grande do Sul: extrativismo, saberes e fazeres locais e conservação ambiental"', que, a partir desse panorama geral de ambientalização social, buscou problematizar: i) de que forma modos de vida específicos podem ser revalorizados, no âmbito deste projeto, em um contexto de conservação da Mata Atlântica?; ii) como se articulam as dimensões locais e da sociedade abrangente, no sentido de fomentar possibi- 
lidades de desenvolvimento rural que tocam também o reconhecimento e o respeito à alteridade?

\section{A PROPOSTA DE PESQUISA}

No referido projeto, propusemo-nos a estudar e a documentar o conjunto de saberes e fazeres relacionados à alimentação, artesanato e agricultura, que caracterizam o modo de vida de segmentos da comunidade rural no Litoral Norte do estado do Rio Grande do Sul (RS), tendo em perspectiva que estes saberes e fazeres são dinâmicos e perpassados pelo universo simbólico dos sujeitos. A partir de técnicas diversificadas (observação direta, entrevistas abertas com registros na forma de diários de campo e principalmente o uso da fotografia e do vídeo), em perspectiva etnográfica (Geertz 1989, Eckert \& Rocha 2008) buscamos acessar o modo de vida dos moradores locais em seus fazeres cotidianos, paralelamente com o compartilhamento dos conhecimentos captados, como estratégias de coleta de dados e ao mesmo tempo de intervenção, uma vez que visávamos também dinamizar o debate sobre estratégias locais para incremento da economia local. Os registros das práticas e as narrativas relacionadas são tomados como elementos fortemente imbricados entre si, remetendo à totalidade de um processo de trabalho e essencial para a compreensão da realidade social, realidade esta em que tradição e modernidade entremeiam-se, em constante recriação e ressignificação. Pretendemos, no presente artigo, destacar algumas interdependências entre a dinâmica ecológica, a trajetória de ocupação do espaço e a construção das especificidades de saberes e práticas, conduzidas pelas narrativas dos moradores locais.

Neste sentido, a transição e integração entre diferentes campos disciplinares das ciências humanas e biológicas apresentam-se no processo de produção desta pesquisa, uma vez que a experiência de condução do projeto e da pesquisa levou-nos a vivenciar parte das tensões entre o natural e o social, que operam tanto no plano epistemológico quanto institucional.

O estudo das variedades de práticas, relacionados à expressiva diversidade biológica e cultural do universo empírico, e dos processos diferenciados de transformações e argumentações relacionadas a essas, podem vir a demonstrar formas distintas de compreender o ambiente, agir sobre ele e transformá-lo, expondo heterogeneidades latentes que tendem a ser agrupadas pela categoria genérica "agricultor familiar", bastante difundida para referenciar este grupo de pessoas. Ainda que a execução de políticas públicas exija, de certo modo, uma definição e unidade dos grupos sociais a que se destinam, de modo que possa haver uma operacionalidade destas, as discussões em torno da definição de agricultor familiar não deixam de englobar o debate acerca da diversidade de situações de vida presentes nesta categoria (relacionada, entre outros aspectos, aos modelos produtivos adotados, ao grau de modernização que internalizaram em suas propriedades, à renda obtida, aos circuitos comerciais e de mercado em que estão inseridos, a 
manutenção de seu patrimônio sociocultural em seu cotidiano, às formas de uso da terra e de percepção de recursos naturais).

O trabalho de registro de saberes e práticas desse grupo social, sabidamente heterogêneo, demonstra ainda antigas e novas especificidades nas formas e estratégias de reprodução social encontradas pelas famílias, indivíduos e comunidades, em constante processo de reprodução e recriação, que ficam invisíveis em debates genéricos, mas que devem ser considerados quando se procuram estratégias de desenvolvimento atentas às necessidades de respeito aos modos de vida dos distintos. Ao salientarmos isso, buscamos demarcar possibilidades de conhecimento acerca do mundo rural trazidas pela metodologia adotada neste trabalho. Partimos de definições como as apontadas por Carneiro (1998) e Wanderley (2003) que destacam a dimensão cultural e simbólica do agricultor familiar, entendendo-o a partir de uma complexidade expressa na "dupla referência à continuidade e à ruptura" com uma tradição camponesa (Cândido 1987, Queiroz 1973).

\section{ENTRE OS AGRICULTORES FAMILIARES NO MUNICÍPIO DE MAQUINÉ: O UNIVERSO EMPÍRICO DA PESQUISA}

O trabalho foi desenvolvido no município de Maquiné, localizado na região de encosta Atlântica no Litoral Norte do RS, que se insere no cenário das políticas conservacionistas globais, ostentando a designação conferida pela UNESCO (Organização das Nações Unidas para a Educação, a Ciência e a Cultura) de Reserva da Biosfera da Mata Atlântica, é também alvo de políticas voltadas a áreas estratégicas para preservação ambiental.

Essa reconhecida importância em termos de conservação encontra-se aliada à grande diversidade cultural, resultante do convívio de descendentes de imigrantes europeus, escravos africanos e povos indígenas, ${ }^{4}$ que ao longo do tempo construíram estratégias próprias de apropriação do espaço e que, somadas à conjuntura sociopolítica regional, condicionam as formas de manejo, cultivo e criação, implementados pelos agricultores locais. O resultado é um complexo arranjo de sistemas produtivos que, para Gerhardt (2002), constituem um universo diversificado, aonde cada região, localidade, propriedade, apresenta características muito distintas.

Nesse contexto, ressalta-se o sistema produtivo implementado nas regiões de encosta que se configura como uma produção agrícola em pequena escala, primordialmente para autoconsumo, com a força de trabalho dependente da unidade doméstica (Kubo 2005). Caracterizada por Gerhardt (2002) como "agricultura colonial-tradicional" é historicamente baseada, enquanto ótica de manejo da terra, para cultivo a partir da queimada da floresta. Nessas propriedades, as atividades são assentadas em tecnologias tradicionais, tanto no que tange à lógica do sistema agrícola, que prevê a rotação de terras e tempo de pousio, como nas variedades de recursos preferencialmente selecionadas. Con- 
juntamente, aparecem diversidades de recursos extraídos, tanto para uso doméstico, agrícola ou de transporte, quanto para complementação da renda, como o extrativismo (Coelho-de-Souza 2003, Kubo e Coelho-de-Souza 2006, Baldauf et al 2007, Suárez et al 2008).

Este modelo de agricultura entrou em crise pela redução das áreas de floresta ao longo dos anos, concomitantemente com a diminuição do tamanho das propriedades pela sua fragmentação, através de herança e formação de novas familias. Neste contexto, o processo de modernização da agricultura se instituiu, estando a maioria dos agricultores excluídos deste padrão tecnológico. Além disso, o incremento da fiscalização e regulação do uso da terra, pelos termos da legislação ambiental, intensificaram algumas dificuldades produtivas vividas pelos agricultores familiares (Ramos 2007). Na perspectiva de Little (2002), as limitações dos agricultores em acessar os recursos de suas propriedades, bem como a proibição de realizar suas atividades habituais de uso do meio biofísico para o autoconsumo, configuram um "preservacionismo territorializante" (op.cit), representado pela noção de controle e planejamento do Estado que exibe controle de áreas extensas.

A atividade extrativista, nesse contexto, explicita a busca pela manutenção de sua alteridade e reinvenção de seus modos de vida, no anseio por persistir e prosseguir a partir do próprio estado de declínio da atividade da roça, a que gerações se dedicaram, marcando, assim, um índice de mudança de um tempo (Kubo e Coelho-de-Souza 2006). Como alerta Bourdieu (1996), apesar de sua dimensão pragmática, a prática (e neste caso a prática extrativista) não significa simples execução, pois comporta dimensão inventiva e criadora. Ao mesmo tempo, por se tratar de uma população de entorno de unidades de conservação, Gerhardt e Almeida (2006) sugere que estes agricultores encontramse em um contexto de luta desigual para invenção de práticas e atribuição de sentidos relacionados ao uso dos recursos naturais. Como explicita Steenbock (2006), as incongruências entre a legislação e os valores, conhecimentos e práticas de manejo locais evidenciam a ausência de participação comunitária para elaboração e gestão dos instrumentos da legislação ambiental.

Tal qual expõe Fleury (2008:50), esse confronto entre diferentes projetos de uso e significação dos recursos naturais resulta na constatação de que o meio ambiente é atravessado por sentidos socioculturais e interesses bastante diferenciados. Evidenciando uma condição assimétrica na valorização desses sentidos, as novas demandas sociais que emergem com a ideia de preservação da natureza e com as éticas ditas "ecológicas", modificam os modos de vida desses agricultores e as formas como eles se relacionam com o ambiente natural (Gerhardt e Almeida 2006). Desta forma, apreender em seu aspecto dinâmico o modo como as populações locais produzem, significam e justificam seus saberes e práticas nas relações cotidianas com seu ambiente, tem nos permitido iniciar 
algumas reflexões no campo da territorialidade. Segundo Little (2002:3), territorialidade é definida como "o esforço coletivo de um grupo social para ocupar, usar, controlar e se identificar com uma parcela específica de seu ambiente biofísico, convertendo-a assim em seu 'território' ou 'homeland'. É construído historicamente, acoplando novas práticas e sentimentos através do cruzamento com perspectivas que - normativas, proibitivas ou valorativas - podem ser visualizadas como "ambientalizadoras", em suas diferentes fontes de legitimidade.

Por outro lado a crescente urbanização e industrialização do país resultou em uma grande concentração de pessoas nas cidades, especialmente nas metrópoles, e em um esvaziamento do espaço rural, caracterizado não somente pela redução demográfica, mas também por uma perda de vitalidade decorrente da valorização de modos de vida urbanos e modernos em detrimento de modos de vida, saberes e práticas tradicionais, que passaram a ser associados a símbolos do "passado", "atraso" e "pobreza" (Wanderley 2009; Menasche e Schmitz 2007).

Nesse contexto, estas pessoas que vivenciaram o esvaziamento em suas comunidades apontam que "desde que inventaram a Mata Atlântica”, as mudanças frequentemente se pautaram por certa intolerância, no sentido da coibição imediata de práticas até então "corriqueiras" mas importantes para a sua reprodução social. Essas mudanças, aliadas à escassez de oportunidades de trabalho e de geração de renda para grande parte dos agricultores, justifi- cam afirmações como "o Ibama pensa que podemos viver de olhar o mato". Nas argumentações destes moradores locais, uma "tal de Mata Atlântica" é percebida no conjunto das medidas fiscalizatórias e punitivas introduzidas, e compreendida como algo fundamentalmente proveniente de fora, orientada por valores, demandas e maneiras de conhecer diferenciadas. Embora atualmente existam ações orientadas para uso e manejo sustentável visando o favorecimentos dos moradores locais, essas propostas ainda se mantém grandemente atreladas aos "de fora".

\section{RESULTADOS DO “ESTAR EM CAMPO'"E DISCUSSÕES ENGENDRADAS}

A fonte para todas estas práticas e dados levantados são os narradores, os quais neste trabalho somaram 39. Destes, 21 homens e 18 mulheres. A maior parte deles agricultores(as) são nascidos no município de Maquiné $(n=34)$, descendentes de imigrantes italianos ( $\mathrm{n}=17)$. A faixa etária mais numerosa dentre os narradores foi aquela entre 61 e 70 anos de idade ( $=15)$.

Ao ouvir antigas e antigos, escutamos lembranças, sentimentos e conselhos, embutidos em relatos de uma vida longa e ativa junto à mata, aos rios, à comunidade, à família e ao trabalho de plantar, criar, colher, processar. Nesse sentido, a escuta qualificada proposta pela etnografia mostrou-se um trabalho por muitas vezes vitalizante, ao oportunizar o contato com saberes e valores de vida cada vez mais raros no modo de vida urbanoindustrial. Como coloca Walter Benjamin, 
"A narrativa tem sempre em si, às vezes de forma latente, uma dimensão utilitária, que pode consistir num ensinamento moral, numa sugestão prática, num provérbio ou numa norma de vida - de qualquer maneira, um narrador é um homem que sabe dar conselhos" (Benjamin 1994:200).

Estes dados são o suporte para uma série de possíveis análises seja na perspectiva acadêmica, seja na perspectiva aplicada, fornecendo elementos para uma proposta de desenvolvimento local. No entanto, buscamos neste trabalho ressaltar os aspectos microscópicos (Geertz 1989) do processo de inserção e interação em campo, dando luz às discussões suscitadas a partir destes, tecendo comentários mais abrangentes relacionados à literatura corrente ou mesmo a questões relacionadas ao desenvolvimento. Resgatamos neste processo a importância da interioridade da experiência temporal do pesquisador como condição para a produção de conhecimento, sobretudo com viés etnográfico, um processo de conhecimento em que meios e fins estão intrinsecamente ligados. Através da composição narrativa que retoma o tempo da ação "em campo", o pesquisador faz coincidir as redes de relações nas quais os atores/comunidades se movimentaram com as que registrou em seu diário de campo, nas imagens e gravações, "numa referência às negociações cotidianas do sentimento de pertencimento ou exclusão (negação voluntária ou exclusão involuntária), onde todos os elementos do conjunto estão numa relação de "intersignificação" (Rocha e Eckert 1998:120).
O trabalho em campo foi de convívio nas localidades do Município e interação junto aos narradores e detentores das práticas e saberes, sustentado pela hospitalidade dos que nos recebem e nas relações de confiança e reciprocidade construídas (Mauss 1974, Sabourin 2009), fazendo-nos (re)conhecer e sermos (re)conhecidas nos espaços cotidianos das localidades - do trabalho na propriedade aos rituais de festas nas igrejas locais, do plantio de milho cunha à moagem no moinho e feitura do pão. Nas continuidades e reflexividades do "estar em campo", buscou-se captar os níveis de representação mais sutis do cotidiano dos agricultores, "possibilitando-nos decodificar o que é pouco visível e apreender, como significativo, aquilo que parece insignificante" (Godoi 1999:7). Assim, visitando agricultores em suas propriedades, ou participando de seus ambientes de trabalho (no moinho de milho, no engenho de açúcar, na coleta de samambaia, no plantio de feijão, nos mutirões comunitários), dispostas a escuta e à observação, fazemos o exercício de desvelar conhecimentos concernentes a outros universos culturais. As memórias suscitadas por meio de depoimentos e histórias que perpassam as entrevistas, são importantes para definição do presente e construção de perspectivas futuras, pois carregam consigo a dimensão de uma realidade social em movimento (Godoi 1999).

Segundo Godoi (1999), as memórias são significativas não apenas para o pesquisador, mas também para os próprios entrevistados, pois constituem redesco- 
bertas para quem as revive, em uma "recuperação positiva da alteridade". Essa recuperação positiva "do outro", possibilitou uma dinâmica recíproca de trocas e produção de vínculo social, fomentada, também, pela contínua retribuição ao acolhimento oferecido pelas pessoas. Essas trocas foram concretizadas através do retorno de fotografias ${ }^{5}$; da oferta de produtos apreciados, encontrados com maior facilidade na capital (na cidade), como a erva-mate; ou também pela compra de gêneros alimentícios produzidos por estas pessoas ou em suas propriedades, como o vinho, o feijão e o ovo caseiro. Como propõe Rechenberg (2004:14), "o retorno ao campo significa admitir que não se tratam apenas de imagens e estórias passíveis de serem lidas ou consumidas, mas de pessoas e suas vidas".

Neste processo de desvelamento de realidades sociais em campo, houve alguns constrangimentos relacionados aos usos de recursos audiovisuais (filmadora, gravador e máquina fotográfica) como instrumentos para representar o outro. Deparamo-nos com nossas próprias limitações em agir com naturalidade diante do uso de tais recursos, principalmente pelas desconfianças e inquietações que podem vir a ser suscitadas em relação aos nossos objetivos de "consumo" de suas imagens. Tais constrangimentos, entretanto, parecem relacionar-se mais à nossa autovigilância em campo, movida também pela preocupação com a dimensão ética da captação de imagens de pessoas e seus modos de vida, do que propriamente explicitada pelos narradores, que em momentos diversos expressaram curiosidade e fascínio diante da possibilidade de apreensão de suas práticas, expressões e gestos por meio desses recursos.

\section{O TRABALHO E A MEMÓRIA NA CONFIGURAÇÃO DOS ESPAÇOS}

Lugar de trabalho por excelência, a propriedade rural é o espaço pelo qual a ação humana opera e elabora um conjunto de elementos dinâmicos articulados entre si (Prado 2008). Assim como mostraram Woortmann e Woortmann (1997), em sua etnografia do trabalho na terra junto a sitiantes de Sergipe, também nas propriedades de Maquiné os micro-espaços da propriedade são conformados e imbricados entre si, com base em uma percepção sistêmica e em conhecimentos da natureza apreendidos cognitiva e afetivamente. A transmissão da terra, seja pela herança ou pela compra, somada à sucessão das práticas de cultivo, resultam na estrutura de suas propriedades rurais como um mosaico dinâmico em constante reorganização, em conformidade ao contexto sócio-político inserido (Prado 2008). Segundo Woortmann e Woortmann (1997), os saberes acumulados são atualizados e novos conhecimentos e práticas incorporados, como "respostas" dinâmicas às mudanças no ambiente natural e social. Trata-se "de uma ativa reconstituição de relações e elementos (velhos e novos, materiais e simbólicos) que ajudam a encarar o mundo moderno" (Ploeg 2006:47). 
Nas atuais propriedades de encosta dos agricultores familiares de Maquiné, alguns elementos se fazem recorrentemente presentes: a casa, o galpão, o quintal, a roça, o potreiro, a capoeira, o capoeirão ${ }^{6}$ e o mato, este último estreitamente relacionado aos demais na dinâmica de mosaico da propriedade. A ocupação destes espaços, que busca satisfazer as necessidades de seus membros e a manutenção da propriedade agrícola, é permeada por relações de hierarquia e gênero, conforme apontado por diversos autores (Heredia 1979, Woortmann e Woortmann 1985, Menasche 2004, Zanetti e Menasche 2007). Na leitura estruturada proposta por tais autores, os espaços da casa, quintal e pátio ficariam sob responsabilidade da mulher ou mãe de família, enquanto a roça e a mata sob responsabilidade do homem, ou pai de família. Tanto o trabalho da mulher quanto dos filhos apareceria como "ajuda", em contraposição àquele realizado pelo pai, este sim considerado "trabalho". Todavia, novas estratégias de reprodução social, criadas a partir de contextos atuais, sob constante intervenção de diferentes instituições e seus mediadores (intermediários, pesquisadores, extensionistas, técnicos locais, turistas e novos moradores), assim como o fortalecimento de uma articulação rural-urbano norteada pela sustentabilidade, pode estar contribuindo para um redesenho dessas divisões de gênero. Ainda é cedo para tecer considerações a este respeito, até mesmo porque a discussão de gênero não consiste no foco deste trabalho. A presença dos recortes de gênero em nosso universo de pesquisa, porém, é forte. Assim, limitamo-nos a apontar que, outras relações de hierarquia e gênero parecem estar se construindo, a partir da ocupação dos espaços da mata e da roça pelas mulheres e pelos jovens. Isso pode estar relacionado a ações de desenvolvimento rural em curso na região, desvelando repercussões das relações de mediação, inclusive da universidade, no município de Maquiné, que tem acontecido de maneira contínua há pelo menos dez anos.

Com alguns dos narradores visitamos antigas estruturas de processamento do alimento produzido localmente: um moinho de milho e descascador de arroz, um engenho de açúcar e melado e um engenho de farinha e massa de mandioca. Estruturas presentes nos espaços da propriedade, que contam muito da história da região: as famílias que há gerações executam esse processamento, a chegada da eletricidade e o abandono da roda d'água e da parelha de bois, o fechamento da grande maioria dos engenhos e moinhos (as relações deste processo com o advento da modernização da agricultura, das indústrias de alimento e da legislação sanitária). Esses espaços de processamento do alimento parecem ser, ao mesmo tempo, rica fonte de informação - pois materializam interações dinâmicas entre modos de produção, economia regional e cultura local - e potencial caminho para proposição de novas ações. Exemplo deste processo foi a realização do I Encontro de Doceiras de Maquiné.7 O "forno de barro", outra estrutura de processa- 
mento de alimentos, registrada em trabalho anterior (Ramos 2007), motivou a realização de um encontro de um dia, no qual valorizou-se e difundiu-se os saberes e práticas das agricultoras que há gerações manejam o forno de barro, produzindo cucas, broas, roscas, rosquetes, bolachas, bolos, pães, merengues, batata-doce e carnes assadas - as doceiras. Os momentos de encontros ou oficinas constituíram-se em uma situação de rememoração de antigos costumes e práticas, de trocas de experiências e reatualização destas práticas, inclusive com a projeção destas atividades como alternativas para a diversificação da renda destas pessoas. Nos termos de Gaston Bachelard (1988), trata-se do processo de constituição de uma duração: a partir objetos e eventos descontínuos, tece-se com o trabalho da memória a constituição de uma continuidade de temporal.

Nesse processo, continuamente perpetuam-se algumas ações: roçar, capinar, plantar. Quintais talhados pela enxada, produzindo alimentos, sempre tem algo a mais, uma planta diferente. Logo no início da carpida, joão-de-barro aparece e fica à vontade catando na terra mexida. São flores, frutas, grãos, saladas. Plantam-se cana, vassoura, bucha, porongo. Inhame e taioba não se confundem. Plantam-se temperos: manjerona, alecrim, alho, cebola. Hortas e flores se misturam ao arvoredo. Remetem posteriormente a colher, comer, oferecer, trocar.

Resultado desse processo contínuo e, dependendo do olhar, invisível, atualmente é possível encontrar grande diversidade de cultivos e cultivares mantidos com agricultores da região, que produzem principalmente para o seu autoconsumo. Os significados e funções atribuídos a esses processos são diversos. Alguns enfatizam que a agricultura pode envolver práticas que beneficiam o ambiente: pode ser diversificadora e recuperadora dos solos e auxiliar no incremento à fertilidade. Nesse sentido, produzir é, também, reproduzir. Não é somente a colheita de alimentos ou produtos que motiva a plantação, alguns plantam por bonito, como comenta senhor que segue plantando trigo, cultivo praticamente inexistente na região e que outrora, caracterizava as paisagens locais. Também, muitos plantios são feitos pelo interesse em se conhecer a planta, a curiosidade em relação a uma nova planta.

Circulam entre agricultores da região feijões de diversos tipos: feijão preto, amendoim e carioca, feijão-de-corda, feijão-de-vagem, feijão guandu. Cultivo exigente com o bom tempo. Quando o ipê $\hat{e}^{8}$ floresce, se diz que crescerá bem. É da experiência de todo agricultor que as condições meteorológicas propiciam melhores ou piores colheitas. Assim, se acontece de chover muito, o feijão pode brotar na vagem, o milho não secar, o aipim apodrecer na terra. Às vezes ocorre de não se colher. Verduras com muita chuva também perdem preço no mercado. Há gente que fala que acostuma, já plantam sabendo. O milho exige terra forte. Depois que brota, se limpa e "se chega terra para agradar o pe’. São encontrados os cultivares de milho cunha, milho taquara, milho 
colorido (branco, vermelho, amarelo) e milho pipoca. Poucos jovens conhecem as variedades crioulas, sendo poucas as famílias que ainda as cultivam. Alguns agricultores reconhecem a origem indígena dessas sementes.

Ao assinalar a convivência humana, de uma gente diversa, com elementos da biodiversidade local e a natureza, busca-se acentuar que a continuidade de práticas relaciona-se aos jeitos de viver o dia a dia, àquilo que se conhece e se observa do meio em que se vive. Por isso, as sensibilidades diante das coisas vivas integram a vida no mundo rural. É como sentir o cheiro das uvas maduras.

Ou quando chega a primavera. Época de nova brotação, que vê-se nos morros e observa-se nos quintais. Há muitas flores, o som dos insetos e os cantos dos pássaros se acentuam: há alguns que cantam apenas nessas épocas, como os sabiás; os sons são bem mais fortes, como também as cores. Bichos do mato se procriam, lagartos e cobras começam aparecer. São exemplos de mudanças sazonais que, em espaços rurais, intervêm nos detalhes da vida, e que orientam trabalho agrícola e ritmo humano.

Isso pode parecer quase insignificante, mas através dos relatos e registros do trabalho de campo trazidos para o texto, buscam exprimir a natureza inspiradora de histórias, que integra práticas e cotidianos de gente que conhece o lugar. São agricultores que seguem vivendo com simplicidade, e que chegam a se acostumar, mas gostam ainda de contar para gente vinda da cidade.

\section{O MATO, ROÇAS, QUINTAIS E ÁGUA}

A relação entre água e floresta é um imperativo para a integridade dos ambientes naturais, e diversos são os efeitos da presença das árvores. As transformações na paisagem decorrentes das atividades produtivas são também interpretadas nesse sentido. Geralmente é reconhecida a importância ao mato pela sua associação com a umidade e uma temperatura amena, mas os relatos são controversos.

Assim, alguns agricultores contam de grotas que secaram, "bicas d'água”onde bebiam água durante os trabalhos nas roças de morro, dizendo que naquele tempo haviam outras vertentes. Nem sempre explicitado de forma clara, mas se em outras falas, percebe-se uma relação, na lógica local, com as plantas e o solo do mato. Há os que até mesmo busca atrair vertente para perto da casa plantando certas árvores. São árvores, como corticeiras e figueiras, que se observam poças de água sob suas copas. Portanto, na percepção local a presença das árvores intervêm na retenção da umidade no ar, na regulação da água superficial, e na suavização da chuva quando esta chega ao solo, efeitos que se imbricam às experiências de vida de agricultores.

Os agricultores mais antigos dizem que hoje há mais chuva para fazer o rio encher, e leva mais tempo para baixar o nível da água. As matas de beira de rio desempenham importante função na manutenção da vazão dos rios: "antes, a água batia no morro e corria para baixo”. A importância das árvores para 
a qualidade da água também se expõe na relação com os peixes que alimenta.

Toda água que corre na bacia do Maquiné deságua na Lagoa dos Quadros, por onde será escoada pela Barra Hidrográfica do Rio Tramandaí. ${ }^{9}$ Essa lagoa integra um conjunto de lagoas de águas doces costeiras, que compõe o sistema lacustre da Planície Costeira do Rio Grande do Sul. Nas áreas próximas às lagoas foi introduzido o cultivo de arroz irrigado, que avançou sobre as áreas alagadas ou úmidas. Em um relato de um dos narradores que se dedica à pesca, conta-nos que uma enchente que inviabilizou a safra (de arroz) do produtor, foi por ação divina, uma vez que esta havia terminado com o berçário de peixes, denotando a continuidade entre o natural e o de certa forma, o divino.

Os principais pescados são a traíra, o jundiá e a tainha, capturados principalmente por rede de espera. Em relação à atividade de pesca, não existem instaladas indústrias de processamento de pescado na região, sendo a manipulação realizada de forma artesanal e a comercialização direta ao consumidor. Observa-se que na maioria das famílias de pescadores existe a prática da venda de mão-de-obra como uma estratégia de busca de uma renda "complementar à pesca" (Cotrim et al, s/d). Além disso, há famílias que confeccionam artesanatos em junco.

Atividades de caça foram extremamente diminuídas, e quando realizada, pelo menos para "os de fora" se costuma falar pouco a respeito. Muitas pessoas falam de bichos que estão aumentando numericamente, como tatus e veados, e de bichos que pas- saram tempo sem serem vistos e vêm reaparecendo. Por outro lado, há quem defenda que no tempo das roças de morro havia maior abundância de alimento para os bichos do mato, e que junto ao abandono das roças os bichos foram embora. Ainda hoje, a chegada dos animais às roças e aos galpões fomenta causos. ${ }^{10}$ Nas roças, pássaros, quati, ratos, paca, macaco, "até graxaim come milho". Cada bicho ao seu costume, deixa suas marcas, aparecendo nos momentos favoritos do crescimento dos cultivos, seja quando semente, broto ou já no milho seco.

De forma geral, ressaltam os agricultores que o mato está de volta. Áreas de floresta estão se desenvolvendo. Os capoeirais ${ }^{11}$ sombreiam e se reduzem para dar lugar ao mato. Para muitos agricultores de Maquiné, o mato que predomina novamente - e que se exprime no verde em contraste ao amarelo das roças do outro tempo - é elemento que distancia de outras formas de viver dessas comunidades.

Por medidas de proteção à floresta, o uso madeireiro de espécies nativas se tornou extremamente dificultado, inclusive para uso na propriedade. Os recursos madeireiros autóctones relacionam-se a proibição de corte e receios diante da possibilidade de multas, gerando tanto o desestímulo ao plantio e manejo da biodiversidade local quanto o enfraquecimento dos conhecimentos associados. Paralelamente, a adoção do eucalipto se difunde, e vem sendo plantado crescentemente, pois ainda aparenta representar a espécie mais segura em termos de possibilitar retorno 
financeiro. Também comercializada, em menor escala, a uva-do-japão, ou uveira, ${ }^{12}$ é uma espécie invasora, principalmente em mais baixa altitude onde é muito grande sua concentração, que servindo de alimento para várias espécies de aves e mamíferos, acaba se dispersando ainda mais.

Muito mais íntima é a relação com as plantas cultivadas, ou deixadas crescer, na proximidade da casa do que em relação às espécies encontradas nas áreas de florestas não manejadas. O costume de buscar frutas no mato é pouco presente, mas muitas dessas frutas nativas são apreciadas. Nos arvoredos que compõem os espaços de moradas, pitangueiras, ingás e bacopari são exemplos de espécies sempre presentes, denotando um movimento de trazer para perto da morada essas espécies florestais, em um incipiente processo de semidomesticação.

O plantio de árvores nos quintais é prática antiga: mamão, araçá, figo, butiá; caqui, pêra, abacate. São plantas de cultivo costumeiro, e que entre quintais e caminhos, ainda se aprende a memorizar onde estão os pés, para quando chegar época de fruto. Limoeiros, laranjeiras ou bananeiras estão entre as espécies frutíferas encontradas frequentemente também em áreas de floresta secundária, caracterizando locais de moradias passadas, quando foram plantadas próximas à taipas ${ }^{13}$ e casas abandonadas ou já inexistentes. Nessa interação entre as pessoas e as plantas, representado pelo processo de acompanhamento do desenvolvimento das plantas, diz-se que estas dependem da presença humana "para ficar bem, dar frutos e crescer; até araticum ${ }^{14}$ dá melhor quando a gente vive perto".

Muitas pessoas em Maquiné conhecem sobre plantas que podem ser utilizadas como remédio, e que são encontradas tanto no mato, como cipó-mil-homens e jaborandi, como em capoeirinhas e beiras de estrada, como arnica, marcela, tansagem. Além disso, muitas plantas medicinais são cultivadas. Nos lugares de hortas, cresce uma diversidade de plantas comestíveis espontâneas como serralha, pena-de-índio, caruru. São plantas alimentícias pouco consumidas. Conta-se que quando as famílias eram mais numerosas, o consumo dessas plantas era mais significativo.

Esboça-se, portanto, uma diversidade de práticas que compõe o arranjo entre a natureza e sua ambientação humana, e que no contexto possibilita verificar a reprodução de diversos elementos da biodiversidade.

\section{BIODIVERSIDADE, CONSERVAÇÃO E TRADIÇÃO}

As narrativas anteriores caracterizamse por um esforço de constituição de uma continuidade apesar das rupturas e mudanças impostas pelo tempo e pelos contextos novos que se apresentam. Nesta seção busca-se evidenciar estas rupturas e as formas pelas quais se dá a interação entre continuidade e ruptura.

De todo este processo, que evidencia uma intensa ocupação de áreas em declive das encostas de morro, o que 
verificamos nas paisagens atuais desta região é que a grande produção agrícola se situa em áreas de várzea, portanto, nos terrenos mais baixos e planos. A intensidade do uso agrícola nessas áreas é decorrente da conciliação de tecnologias em torno da mecanização, adubação, quimificação.

Importante considerar que o processo de modernização da agricultura teve início também através do estabelecimento de novos cultivos por volta da década de 1960, até então, quase inexistentes, mas que acabaram se sobressaindo. Esses cultivos se associam a uma produção tecnificada e exigente de alto grau de aportes externos, como o fumo, as olerícolas e a banana tipo prata (Cotrim et al, s/d). A dependência crescente de insumos externos, por exemplo, no caso da bananicultura, conforme Vivan (2002) relaciona-se à pressão por aumento de produtividade e pela demanda por um fruto de boa aparência, o que ocasionou um aumento do uso de agroquímicos e outros insumos, triplicando os princípios ativos recomendados e/ou registrados para a cultura em 30 anos.

É possível observar que a adoção de práticas agrícolas fomentadas pelo modelo produtivista se fortaleceu com as dificuldades impostas pela legislação ambiental à agricultura tradicional. A proibição da prática de queimada, por exemplo (recorrentemente citada como um índice de mudanças de comportamentos pelos narradores), somada à pouca valorização do trabalhador rural e/ou produtos agrícolas tradicionais, como o feijão e o açúcar mascavo, e consequente, a redução da mão-deobra, potencializa a substituição dos trabalhos de roçadas e capinas pelo uso de herbicidas e adubos sintéticos. Assim, muitas famílias de agricultores de Maquiné colocam-se como testemunhas de uma penalização da agricultura tradicional pela intensificação da fiscalização ambiental, ao mesmo tempo em que ciclos de agricultura produtivista (fumo, hortaliças, arroz, gado de corte) vem se sucedendo, com seus impactos para a saúde humana (pela carga de substâncias tóxicas, imposição de um ritmo de trabalho diferenciado e aumento do endividamento) ambientais e sociais (percebidos pela degradação de recursos naturais, bem como empobrecimento de famílias que ficaram à margem do processo de modernização agrícola).

Conforme os relatos, com o abandono das roças em áreas de morros alguns cultivares passaram a não serem plantados como abóboras crioulas e milho cunha, e também a produção de cultivos como milho e feijão se reduziu gradualmente. Mudou também a maneira de fazer o trabalho.

Desta forma o espaço do mato é constituído por recortes que expressam maior ou menor grau de intervenção humana. Mesmo diante das condicionantes leis ambientais, as seleção de áreas de mato para queimada, o extrativismo de recursos vegetais (fibras, frutas e remédios) e a caça são cuidadosamente praticadas, além de abrigar e estarem relacionadas, de modo mais genérico, a entes das histórias locais, como a mãe do ouro, e o gigante do mato. ${ }^{15}$ Conforme aponta Gerhardt (2002), o mato está 
entre os elementos constitutivos da "identidade do agricultor. Tal relação é explicitada por (Carneiro 1998::163), segundo a qual "o reconhecimento de um determinado espaço como próprio ao indivíduo, à família e ao grupo mais amplo, é informado pela memória coletiva herdada de gerações anteriores. Os marcos ou pontos de apoio dessa memória são os próprios componentes da paisagem: rios, morros, montanhas, árvores..." De acordo com Woortmann e Woortmann (1997), o mato é base de construção para qualquer dos espaços da propriedade: após derrubado, torna-se roça, que se torna capoeira fina, que evolui para capoeira grossa, que novamente se torna roça, até que o solo, enfraquecido, "descansa" em pousio; o mato opõe-se à roça ao mesmo tempo em que mantém uma estreita relação com ela; é transformado em terra de trabalho pela queimada, sob a forma de chão para a roça." Esta relação possibilita conceber o mato como "matriz"16 da paisagem e do trabalho, representando aquilo que é fonte, ou origem, o elemento de onde partem e por onde chegam bichos, sementes, recursos e plantas. Esta apreensão, modificação e construção de novos espaços a partir do mato relacionase com a perspectiva de Descola (1997:249), segundo o qual "a natureza é uma construção social em perpétuo vir-a-ser". Assim, os saberes dessas populações na relação com a natureza são decorrentes do histórico processo de construção e reconstrução dessa natureza, "neste perpétuo vir-a-ser".
Na perspectiva engendrada por Sardan (1995), esse dinamismo de construção e reconstrução não é restrito à relação com a natureza: também em seu meio social, os saberes populares não são estáticos ou definidos apenas pela categoria "tradicional". Eles apresentam, pois, dimensões inovadoras, incorporando novos conhecimentos, se transformando e evoluindo, rompendo-se, assim, com a noção de uma tradição estática, ahistórica e atemporal. Assim, a tradição não é o passado que sobrevive no presente, mas o passado que, no presente, constrói as possibilidades do futuro (Giddens 1991).

Nestas articulações entre tradição e modernidade no universo sociocultural em estudo, permanecem práticas diversas, com seus passados reelaborados pela incorporação, atualização e inovação de conhecimentos. Ainda assim, é visível e incontestável o abandono ou mesmo desagregaçãode alguns saberes e práticas locais como resultado da incorporação de lógicas capitalistas de produtividade e seus novos modos engendrados de se vincular e de se relacionar com a terra. O passado, neste sentido, retém elementos que já não podem existir, como os morros cobertos não pelo mato atual, mas por uma infindável variedade de cultivares, que faziam daquela região e da atividade agrícola, prósperas e fartas, como expressa o forte sentimento saudosista percebido no contato com nossos narradores. Podemos perceber, na concepção dos nossos interlocutores, que a fartura da roça foi substituída por uma subsistência simplificada, onde a maior 
parte dos gêneros produzidos antes pelas famílias passaram a ser substituídos por produtos vindos do comércio. Percebe-se a ressignificação do ser agricultor, que vem desistindo de plantar, pois a colheita de sua roça não tem coberto os custos da produção. Com o êxodo rural, em muitas propriedades de encosta restaram somente os habitantes mais velhos, que vem gradualmente diminuindo suas áreas de plantio, quantidade e variedade de produtos cultivados.

O panorama obtido a partir do encontro e aproximações com os moradores locais e suas narrativas nos dá uma boa ideia de diferentes paisagens e suas correlações com os processos de ocupação das áreas, nas práticas e saberes associados e, sobretudo, como se conformam as mudanças, apropriações e reinvenções.

E como vêem os narradores a transformação de sua cultura? Essa nostalgia, já relatada, aparece como um elemento valorativo do passado, onde existiam muitas dificuldades, muito trabalho, mas era muita fartura e juventude. Muitos elementos novos foram incorporados ao cotidiano rural, como o telefone celular, o fogão a gás, a geladeira e o congelador. A luz chegou até em lugares bem distantes, trazendo consigo outras transformações como a televisão, muito comum nas casas, e gradativamente a internet.

O moinho do Seu Pedro é um bom exemplo dessas transformações. Antigamente, ao lado do moinho passavam dois pequenos riachos, que faziam mover a roda d'água. Ele nos conta que há muitos anos os rios mudaram o caminho e a família passou a utilizar a luz para a moagem. Os equipamentos do moinho, que eram de sua bisavó continuam os mesmos, sendo adaptados ao uso da energia elétrica. Seu Darci, também conhecido tocador de gaita e declamador, relatou que existiam 29 rodas d'água na região. Algumas chegavam a oito metros de altura. "Mas agora não tem mais água", ele nos fala.

O milho cunha é lembrado como o melhor para fazer polenta, ${ }^{17}$ pois só ele dá a "liga" necessária (Ramos 2007). Apesar disto, hoje a maioria dos agricultores não cultiva esta variedade, tendo o milho híbrido, ou como é chamado localmente híbrio, conquistado muito espaço devido à sua grande produtividade. O reconhecimento do milho cunha como o melhor para a polenta parece ser um consenso entre nossos entrevistados e também registrado em trabalhos anteriores (Ramos 2007). O bíbrio produz mais, mas não é bom, nem para o trato dos animais. Então porque continuam plantando-o? Em muitas propriedades, como na do seu João “Quinhentos”, que reproduz esse mesmo discurso em relação ao milho cunha, já há alguns anos são plantados os dois tipos; esse ano deixou de plantar a variedade crioula para plantar só o híbrido. Dona Santina, em outra propriedade, ao saber que seu cunhado, que mora alguns quilômetros adiante, ainda planta o cunha, mostrou-se surpresa dizendo que iria pegar algumas sementes com ele. Mas será que plantar o milho é realmente o importante? Ou mais importante é a consensualidade do discurso? 


\section{CONSIDERAÇÕES FINAIS}

Todos estes processos remetem a um "sistema complexo entrecortado por relações sociais flexíveis e carregadas de conflitos que se definem a partir dos interesses dos agentes locais com capacidades de negociação distintas" (Carneiro 1998:58). Contudo, a disponibilidade de receber elementos culturais alheios é controlada pela própria comunidade, processo que Rambaud (1969 apud Carneiro 1998:65) identifica por "aculturação livre", que mantém a comunidade com "autonomia sobre a forma e os limites das mudanças". Apesar disto, alguns elementos se modificam de forma que não podem ser controladas pelos atores locais. Algumas das substituições acabam afetando a autonomia dessas populações, como a adoção de sementes híbridas, que faz com que as sementes tenham que ser compradas a cada safra, juntamente com os insumos.

Outra reflexão tem estado muito presente no debate em nosso grupo. Como registrar os saberes e práticas, com suas transformações materiais e simbólicas, sem realizar um julgamento valorativo dessa transformação? Ou melhor, como a discussão, trazida por políticas como as que valorizam o patrimônio cultural ou a agrobiodiversidade, se relacionam com seu "público alvo"? Como será percebido esse interesse, por pessoas da cidade, pelas práticas do passado? Que tipo de reação esse tipo de política pode gerar em comunidades rurais? Uma questão tem nos parecido central, a necessidade deste tipo de política não con- gelar essas práticas e conhecimentos, passando o tradicional a ser definido por um conjunto de regras estáticas. Além disso, a preservação de algumas práticas choca-se diretamente com a legislação ambiental e sanitária. Só esta questão geraria uma série de frutíferos debates. De qualquer forma, essas comunidades rurais e seus modos de vida só poderão ser mantidos em sua plenitude se puderem novamente gerar um justo sustento a essas populações.

São variadas as dimensões que se articulam e operam atualmente na normatização das condutas desses agricultores, o que às vezes culmina na criminalização de atividades outrora cotidianas. Os territórios visitados são produtos históricos de processos biofísicos, políticos e de modos culturalmente específicos de atuar. Valorizar alguns desses aspectos culturais e promover uma interiorização dos direitos e dos argumentos ambientais, junto à "recontextualização do passado" conforme Maria José Carneiro, tem a possibilidade de desencadear um questionamento das políticas públicas vigentes, buscando recompor a livre expressão de suas manifestações territoriais e desta forma ampliando o poder de escolha local.

Em um processo aparentemente contraditório, saberes e práticas tradicionais relacionados aos modos de vida das famílias rurais foram e continuam sendo, ao mesmo tempo, desprestigiados por alguns - por aqueles que protagonizam e divulgam a modernização; desconhecidos e por grande parte dos filhos e netos da geração de idosos do município - e demandados por outros 
- visitantes e turistas urbanos - que buscam nessas tradições e paisagens rurais um referencial de pureza, autenticidade e sustentabilidade aparentemente perdidos nas cidades.

Além de valorados de formas contraditórias, dependendo da situação e da pessoa que os pratica ou comenta, os saberes e práticas do mundo rural não são estáticos, mas reinventam-se a partir de novas condições vividas pelo grupo, assim como o saber-fazer descrito por De Certeau (1994). Esse saber intimamente ligado ao fazer, joga e subverte com a lógica dominante, apropriando-se dos elementos externos introduzidos no grupo, dando a eles novos significados e aplicações. Por isso é um saber em constante transformação.

"O saber-fazer camponês não é estático. Através de gerações, ele acumula experiências e pode, em certos momentos, retomar técnicas desenvolvidas no passado, deixadas como que 'entre parênteses' na memória do grupo, como no caso da malhada, só reempregada quando se tornou necessário passar da lavoura extensiva para a intensiva. Ao mesmo tempo que resgatam o passado, introduzem inovações, como fertilizantes, sementes, variedade de plantas e produtos." (Woortmann e Woortmann 1997:177).

Vemos que o trabalho e o saber do agricultor interagem continuamente. No rural, entre famílias de agricultores, a transformação dos modos de fazer e dos saberes associados muitas vezes é interpretada como perda de identidade dos campesinos ou visto como o fim do rural. Hoje, cinquenta anos após o auge da Revolução Verde, podemos pensar que, juntamente com as transformações materiais, também a lógica camponesa vem se reinventando, como sugere De Certeau (2003), sendo possível percebermos processos de constante atualização a partir da transformação da paisagem, dos processos produtivos, do papel que exerce a cidade, da influência dos meios de comunicação.

Esses novos significados do rural, das práticas desenvolvidas em seu espaço e os saberes associados, não estão dados. É nessa possibilidade de (re) construção de identidades e significados do rural que entendemos o trabalho de registro e valorização de saberes locais relacionados à agricultura, alimentação e artesanato e do fomento a relações de complementaridade entre campo e cidade.

"As transformações mais recentes do meio rural são o resultado de fatores externos e internos. No primeiro caso, trata-se dos efeitos das novas relações econômicas e políticas, dominantes em um mundo cada vez mais internacionalizado, sobre as formas de funcionamento e regulação da produção agrícola e de valorização do meio rural. (...) Internamente, o meio rural sofrerá um profundo processo de diversificação social e suas relações com o meio urbano perderão definitivamente o caráter de antagonismo, em benefício das relações de complementaridade" (Wanderley 2009:212).

Os narradores registrados correspondem ao narrador de Walter Benjamin 
(1994): transmitem memórias, saberes, tradições que vem de longe, que vem de dentro, que se misturam ao seu saber. Não são informações, descartáveis. Possuem densidade; fazem refletir; marcam. Ensinam e permanecem vivas na memória de quem as ouve. Dizem mais do que as palavras. Transmitem valores. Podem ser recontadas por outros narradores. E formam esses novos narradores (Benjamin 1994).

Esses narradores falam de memórias vividas, que ao serem contadas são ressignificadas e atualizadas, conforme afirma Halbwachs (2006). Ajudam-nos a compreender um pouco dos significados envolvidos em seus saberes. Eles contam memórias de um passado vivido. Contam sobre um saber-fazer, aprendido há tanto tempo e tão praticado, que constitui quem o conta. E também de um aprender a fazer, que envolve esse resgate de memória.

"Há, portanto, uma inteligência narrativa que está em relação estreita com a inteligência prática e que sugere uma ligação entre o ato de contar histórias e a própria experiência cotidiana desses narradores, ou seja, a compreensão narrativa refere-se tanto à compreensão da linguagem do 'fazer', da ação no mundo, quanto à tradição cultural das intrigas, das estórias, dos modos de contar" (Ricoeur 1994:84).

Segundo Maurice Halbwachs (2006:23), "ninguém pode se lembrar realmente a não ser em sociedade". Porque nossa memória, mesmo dos momentos que aparentemente vivemos sozinhos, é constituída a partir de um pertencimento a um grupo. E só pensamos a partir das ideias desse grupo e de nosso posicionamento em um determinado tempo e espaço.

Partindo então do olhar, anteriormente apresentado, do rural como espaço em transformação, onde os saberes camponeses são atualizados a partir dos novos contextos vividos, destacamos o papel da memória coletiva e dos seus narradores para o fortalecimento das $\mathrm{CO}_{-}$ munidades rurais e para a construção de planos de futuro para esses grupos.

\section{NOTAS}

${ }^{1}$ Como nas configurações caracterizadas entre estabelecidos e "outsiders", tão bem relatado por Elias e Scotson (2000)

${ }^{2}$ Como exemplo podemos citar as propostas que se firmam em torno da noção de gestão compartilhada (Calsson e Berkes 2005, Seixas e Kalikoski 2009, entre outros)

${ }^{3}$ Este Projeto foi desenvolvido pela equipe do grupo DESMA/PGDR/UFRGS Núcleo de Estudos em Desenvolvimento Rural Sustentável e Mata Atlântica, em parceria com a ONG Ação Nascente Maquiné e financiado pelo $\mathrm{CNPq}$ sob coordenação do professor Lovois de Andrade Miguel. O presente trata das atividades referentes a um dos subprojetos "Agricultura, alimentação e artesanato no Litoral Norte do RS: registro e identificação de saberes e práticas entre agricultores familiares", que, sem perder de vista o todo, constitui o foco deste trabalho. O Projeto iniciou em duas fases ou funcionou de março de 2008 até dezembro de 2010.

${ }^{4} \mathrm{Na}$ região visualiza-se intensa presença de indígenas Guarani, com Terras Indígenas demarcadas ou em vias de regularização, e 
também remanescentes de quilombolas, na região conhecida por Morro Alto.

${ }^{5}$ As fotos selecionadas para a impressão formaram um registro dos retornos aos informantes. Foram confeccionados quatro álbuns fotográficos com as seguintes temáticas: a) atividades de projetos em Maquiné; b) Ternos de Reis da Linha Solidão; c) Festas Comunitárias; d) narradores diversos. Os álbuns circularam pelas diferentes Linhas e diferentes mãos, fazendo conhecer os narradores e rendendo boas conversas. Ao final do trabalho iniciou-se um exercício de seleção de fotografias de cada informante, que formam álbuns individuais, que vem sendo entregues aos narradores (DeCarli 2010).

6 Os termos "capoeira" e "capoeirão" remetem a diferentes estágios de regeneração da vegetação.

${ }^{7}$ Uma das atividades que foi realizada no período do projeto.

\section{${ }^{8}$ Tabebuia sp.}

${ }^{9}$ Segundo(Cotrim et al, s/d), a região da bacia do Tramandaí engloba 16 lagoas costeiras, sendo as principais as lagoas Itapeva, Malvas, Quadros, Barros e Fortaleza. Essas lagoas são ligadas por barras que têm uma função ecológica importante de união dessas com as lagunas do estuário de Tramandaí, possibilitando, por exemplo, a migração de espécies de peixe.

${ }^{10}$ Histórias, relatos.

${ }^{11}$ Áreas de vegetação em regeneração.

${ }^{12}$ Hovenia dulcis Thunb.

${ }^{13}$ Antigas cercas para delimitação de propriedades ou isolamento de áreas de criação, construídas com pedras.

${ }^{14}$ Espécie nativa, característica de área de mato.

15 Trata-se de seres sobrenaturais presentes no imaginário local. A mãe do ouro, mito similar ao boi-tatá, se manifesta por meio de uma bola de fogo em algum ponto do mato. O gigante do mato parece surpreender aqueles que superexploram $o$ mato. Muitos autores têm demonstrado que os mitos codificam relações ecológicas intrincadas entre o mundo natural e o humano, evidenciando a maneira como as inter-relações ecológicas são percebidas (Posey 1987).

16 A palavra "matriz", etimologicamente, deriva da raiz mater- 'mãe', assim representada em todas as línguas indo-europeias, pode aplicar-se à: segunda mãe, madrinha, árvore que deita rebentos, tronco, origem, madre, útero, ventre, matrícula, registro público, metrópole. No campo da ecologia de paisagens, é a unidade que controla a dinâmica da paisagem (Forman, 1995 apud Metzger), podendo também ser reconhecida pela predominância.

17 Comida típica, preparado à base de farinha de milho cozida com água.

\section{REFERÊNCIAS}

Bachelard, G. 1988. A dialética da duração. São Paulo: Ática.

Baldauf, C.; N. Hanazaki \& M. S. Reis. 2007. Caracterização etnobotânica dos sistemas de manejo de samambaia-preta (Rumohraadiantiformis (G. Forst) Ching Dryopteridaceae) utilizados no sul do Brasil. Acta Botanica Brasilica 21 (4): 823-834.

Benjamin, W. 1994. O narrador. Considerações sobre a obra de Nikolai Leskov, in Magia e Técnica, Arte e Politica. Obras escolhidas 1. W. Benjamin, pp. 197-221. São Paulo: Brasiliense.

Bourdieu, P. 1996. Raz̃oes práticas. Sobre a teoria da ação. Campinas: Papirus.

Candido, A. 1987. Os parceiros do Rio Bonito. São Paulo: Duas Cidades.

Carlsson, L. \& F. Berkes. 2005. Co-management - concepts and methodological im- 
plications. Journal of Environmental Management 75(1): 65-76.

Carneiro, M. J. 1998. Ruralidade: novas identidades em construção. Estudo Sociedade e Agricultura 11: 53-75.

Cnumad - Conferência das Nações Unidas sobre Meio Ambiente e Desenvolvimento. 1995. Agenda 21. Brasília: Câmara dos Deputados.

Coelho-de-Souza, G. 2003. Extrativismo em área de reserva de Mata Atlantica no Rio Grande do Sul: um estudo etnobiológico em Maquiné. Tese de Doutorado. Programa de Pós-Graduação em Botânica, Universidade Federal do Rio Grande do Sul, Porto Alegre, Brasil.

Cotrim, D. S.; D. Garcez; L.A. Miguel. s/d. Litoral Norte do Rio Grande do Sul: sob a perspectiva de diferenciação e evolução dos sistemas agrários. Relatório de Campo. Inédito.

De Carli, A. P. 2010. Três histórias rurais narrativas visuais e memória de agricultores no Litoral Norte do Rio Grande do Sul. Trabalho de conclusão de curso. Curso de Ciências Sociais, Universidade Federal do Rio Grande do Sul, Porto Alegre, Brasil.

De Certeau, M. 2003. A invenção do cotidiano. $A$ arte de fazer. Petrópolis: Vozes.

Descola, P. 1997. Ecologia e cosmologia, in Faces do tropico úmido. Editado por E. Castro \& F. Pinton, pp. 214-261. Belém: UFPA, NAEA, CEJUP.

Diegues, A. C. (org.) 2000. Etnoconservação. São Paulo: Hucitec/Nupaub.

Eckert, C. \& A. L. Rocha. 2008. Etnografia: saberes e práticas, in Ciências Humanas: pesquisa e método. Organizado por C. R. J. Pinto \& C.A.B. Guazzelli, pp. 9-24. Porto Alegre: Editora da Universidade.

Elias, N. e J.L. Scotson. 2000. Os estabelecidos e os outsiders. Sociologia das relações de poder a partir de uma pequena comunidade. Rio de Janeiro: Zahar.
Fleury, L.C. 2008. Cerrado sob disputas: conflitos socioambientais e representações sociais em torno do Parque Nacional das Emas, GO. Dissertação de Mestrado. Programa de PósGraduação em Desenvolvimento Rural, Universidade Federal do Rio Grande do Sul, Porto Alegre, Brasil.

Forman, R.T.T. \& M. Godron. 1986. Landscape ecology. New York: Wiley \& Sons Ed.

Geertz, C. 1989. A Interpretação das Culturas. Rio de Janeiro: LTC.

Gerhardt, C. 2002. Agricultores familiares, mediadores sociais e meio ambiente: a construção da "problemática ambiental" em agroecossistemas. Dissertação de Mestrado. Programa de Pós-Graduação em Desenvolvimento Rural, Universidade Federal do Rio Grande do Sul, Porto Alegre, Brasil.

Gerhardt, C. H. e Almeida, J. 2003. "Ecologização" dos agricultores ou construção de novos processos de dominação? A problemática ambiental nos espaços rurais. Anais do XI Congresso Brasileiro de Sociologia, CDROM, Campinas, set. 2003.

Gerhardt, C, H. e J. Almeida. 2006. A problemática do meio ambiente nos espaços rurais: o exercício do poder e a legitimidade da dominação. Raízes 25 (1/2): 10-25.

Giddens, A. 1991. As consequências da modernidade. São Paulo: Unesp.

Godoi, E.P. 1999. O trabalho da memória: Cotidiano e bistoria no sertão do Piauí. Campinas: UNICAMP.

Halbwachs, M. 2006. Memória Coletiva. São Paulo: Vértice.

Heredia, B. M. A. 1979. A morada da vida: trabalho familiar de pequenos produtores do Nordeste do Brasil. Rio de Janeiro: Paz e Terra.

Kageyama, A. A. 2008. Desenvolvimento rural: conceitos e aplicação ao caso brasileiro. Porto Alegre: UFRGS. 
Kubo, R. R. 2005. Coletores de samambaiapreta e a questão ambiental: estudo antropológico na área dos Fundos da Solidão, município de Maquiné, Encosta Atlântica no Rio Grande do Sul. Tese de Doutorado. Programa de PósGraduação em Antropologia Social, Universidade Federal do Rio Grande do Sul, Porto Alegre, Brasil.

Kubo, R. R. \& G. Coelho-de-Souza. 2006. Tempo do artesanato: etnografia do processo de busca de uma alternativa econômica para agricultores extrativistas em área de Mata Atlântica no RS, in Atualidades em Etnobiologia e Etnoecologia. Organizado por R. Kubo et al., pp. 245-258. Recife: NUPPEA/Sociedade Brasileira de Etnobiologia e Etnoecologia.

Lopes, J. S. L. 2006. Sobre processos de ambientalização dos conflitos e sobre dilemas da participação. Horizontes Antropológicos 12: 31-64.

Little, P. E. 2002. Territórios sociais e povos tradicionais no Brasil:por uma antropologia da territorialidade. Brasilia: Série Antropologia.

Mauss, M. 1974. Sociologia e antropologia. São Paulo: EPU/Ed. USP.

Menasche, R. 2004. Capinar: verbo conjugado no feminino? Notas de pesquisa sobre gênero e percepções de risco na agricultura familiar. Cuadernos de Desarollo Rural 53: 25-36.

Menasche, R. \& L.C. Schmitz. 2007. Agricultores de origem alemã, trabalho e vida: saberes e práticas em mudança em uma comunidade rural gaúcha, in Agricultura familiar à mesa: saberes e práticas da alimentação no Vale do Taquari. Organizado por R. Menasche, pp. 78 89. Porto Alegre: Editora da UFRGS.

Metzger, J. P. 2001. O que é ecologia de paisagens? Biota Neotrópica 1(1-2): 1-9.

Ploeg, J. D. 2006. O modo de produção camponês revisitado, in Diversidade da Agricultura Familiar. Organizado por S. Schneider, pp. 13-
54. Porto Alegre: Editora da UFRGS.

Posey, D. A. 1987. Etnobiologia: teoria e prática, in Suma etnológica brasileira: etnobiologia. Editado por B. G. Ribeiro, pp. 15-25. Petrópolis: Vozes.

Prado, P.I. 2008. Paisagens entre natureza e cultura. Ensaio Projeto São Luiz do Paraitinga (SLP). Departamento de Ecologia da Universidade de São Paulo.

Queiroz, M. I. P. 1973. O sitiante tradicional e a percepção do espaço, in $O$ campesinato brasileiro, pp. 48-71. São Paulo: Vozes.

Rambaud, P. 1969. Société rurale et urbanisation. Paris: Seuil.

Ramos, M. O. 2007. A "comida da roça" ontem e hoje: um estudo etnográfico dos saberes e práticas alimentares de agricultores de Maquiné (RS). Dissertação de Mestrado. Programa de Pós-graduação em Desenvolvimento Rural, Universidade Federal do Rio Grande do Sul, Porto Alegre, Brasil.

Rechenberg, F. 2004. Os dilemas do uso da fotografia na restituicão da palavra do Outro: um estudo sobre imagem e memória na Barra do Ouro - RS. Monografia de conclusão de curso. Faculdade de Jornalismo, Universidade Federal do Rio Grande do Sul, Porto Alegre.

Ricoeur, P. 1994. Tempo e Narrativa. Campinas: Papirus.

Rocha, A.L.C. \& C. Eckert. 1998. A interioridade da experiência temporal do antropólogo como condição da produção etnográfica Revista de Antropologia 41(2): 107-136.

Sabourin, E. 2009. Comunidades camponesas e organização social da produção, in Camponeses do Brasil: entre a troca mercantil e a reciprocidade, pp. 28-77. Rio de Janeiro: Garamond.

Sachs, I. 2000. Caminhos para o desenvolvimento sustentável. Rio de Janeiro: Garamond.

Sardan, J.P.O. 1995. Anthropologie et développment- essai en sócio-anthropologie du changement social. Paris: Karthala. 
Schneider, S. 2010. Situando o desenvolvimento rural no Brasil: o contexto e as questões em debate. Revista de Economia Politica 30 (3): 511-531.

Seixas, C. \& D.C. Kalikoski. 2009. Gestão participativa da pesca no Brasil: levantamento das iniciativas e documentação dos processos. Revista Desenvolvimento e Meio Ambiente 20: 119-139.

Steenbock, W. 2006. Etnobotânica, conservação e desenvolvimento local: uma conexão necessária em políticas do público, in Atualidades em Etnobiologia e Etnoecologia. Organizado por R. Kubo et al., pp. 65-84. Recife: NUPPEA/Sociedade Brasileira de Etnobiologia e Etnoecologia.

Suárez, J. E. A.; G. P. Coelho-de-Souza \& L. A. Miguel. 2008. Extrativismo da samambaia-preta e a geração de renda para a agricultura familiar, in Extrativismo da samambaia-preta no Rio Grande do Sul. Organizado por G. P. Coelho-de-Souza; R.R. Kubo \& L.A. Miguel, L. A., pp. 139-156. $1^{\circ} \mathrm{ed}$. Porto Alegre: Editora da UFRGS.

Vivan, J. L. 2002. Bananicultura em sistemas agroflorestais no Litoral Norte do RS. Agroecologia e Desenvolvimento Rural Sustentável 3(2): 1-20.

Wanderley, M. N. B. 2003. Agricultura familiar e campesinato: rupturas e continuidade. Estudos Sociedade e Agricultura 21:42-60.

Wanderley, M. N. B. 2009. O mundo rural como um espaço de vida: reflexões sobre a propriedade da terra, agricultura familiar e ruralidade. Porto Alegre: Editora da UFRGS.

Woortmann, F. E. \& Woortmann, K. 1997. O trabalho da terra: a lógica e a simbólica da lavoura camponesa. Brasília: Editora Universidade de Brasília.

1985. A comida, a familia e a construção do gênero feminino. Trabalhos de Ciências Sociais. Série Antropologia 50: 1-43.
Zanetti, C. \& R. Menasche. 2007. Segurança alimentar, substantivo feminino: mulheres agricultoras e autoconsumo, in $A$ agricultura familiar à mesa: saberes e práticas da alimentação no Vale do Taquari. Organizado por R. Menasche, pp. 130-141. Porto Alegre: Editora da Ufrgs.

Recebido em 25/06/2013.

Aprovado em 10/08/2013. 